\title{
SHAREABLE CITY, REGENERATED BY MAKING
}

\author{
C. CELLUCCI \& M. DI SIVO \\ Department of Architecture, G.D’Annunzio University, Chieti-Pescara, Italy.
}

\begin{abstract}
Today, most theories on the regeneration of the territory and the built environment are based on the paradigm of scarcity, i.e. the conviction that all the resources already exist, and are scarce, and that the choices only concern how to allocate said resources. The same word - economy - comes from the Greek word oıкоvонí $\alpha$, which doesn't only contain the 'management of a house or a household', but also a sense of 'parsimony'. The sociologist and philosopher Feyerabend adopts a very different approach with his theory on the 'Conquest of Abundance', in which he suggests that individuals 'conquer' abundance and manage such abundance with others, through the creation of production strategies based on principles of cooperation among the various players of the process, on the willingness of all involved parties to implement virtuous cooperation in the organisation of local construction chains.

According to this theory, there is no separation between producers and consumers anymore, but today we talk about Prosumer, citizens become responsible for the space they live in and organise to 'make' the space in the first person. The paper identifies some useful paradigms to guide the methodological and operating choices in the regeneration processes based on the creative skills of the inhabitants.
\end{abstract}

Keywords: abundance, collective intelligence, prosumer, resilience, sharing economy.

\section{INTRODUCTION}

For most part of history, the transformation of the environment was an integral part of people's lives, the inhabitants were in contact with each other and the knowledge of the community life, its culture and its territory made them all 'designers' and able to understand the meanings of building in all respects. Today the inclination for homologation in the transformation of the territory results in urban interventions being performed by parties that are not part of the community for which the design is being made, as a consequence the true needs of the inhabitants, as well as the sense of community and belonging that are essential in the creation of a sustainable and resilient city, are often unspoken.

After all, urban life is constantly evolving, and so are the needs and use of the common property of its inhabitants. Community spaces, which used to be made up of parks, libraries, markets and schools, funded and managed with public funding, evolve toward forms of organisation that still promote the community identity, the cultural expression, the learning, and a feeling of belonging, but they do so through a new management model. Such a model does not burden public budgets, but is based on the principles of active community participation and the coordination of multi-disciplinary groups. The main approaches to the management of a territory and its resources are analysed below in order to define the main paradigms of the participated regenerative process. 


\section{FROM SUSTAINABILITY TO RESILIENCE - FROM SCARCITY TO ABUNDANCE}

In a matter of a few years we have moved from the age in which everything was labelled as 'sustainable' to an age whose main concept is 'resilience'. At the base of sustainability, there's the idea to strike a balance, through an effective management and control of change according to a 'fail-safe' mind-set. The more recent thinking about resilience on the contrary comes from the idea that many systems, including cities, are 'safe to fail' systems and tackles uncertainty through adaptability, which allows the system to suffer a shock and/or perturbation without causing significant alterations in its functional organisation [1]. Where sustainability aims at balancing the world, resilience searches ways to manage an unbalanced world. The dichotomy between sustainability and resilience refers to another dichotomy between the two approaches to the management of the planet's resources: Scarcity and abundance. Achterhuis [2] suggests that in the western world humankind confronts itself with 'abundance', but experiments the opposite: There's opulence of abundance, but at the same time the discomfort of scarcity. He refers to a feeling that 'it is never enough', the choices are so many that we are immersed in a permanent feeling of scarcity. Thinking in terms of 'scarcity' and 'abundance' may be considered as a continuum with two extremes. These are made up of two contradictory paradigms on the natural distribution of (tangible and intangible) resources on earth. Scarcity is based on the principle that all resources already exist, and are scarce, and that the choices concern how to allocate them in order to strike a balance. Such an approach refers to sustainable development theories, according to which the current needs of users can be met without compromising the possibilities for enjoyment of future generations. It is clear that, today, the interaction of humankind and territory is based on the paradigm of 'scarcity' which has fed the sustainable development theories, the same word - economy comes from the Greek word огкоvонí, which doesn't only contain the 'management of a house or a household', but also a sense of 'parsimony'. Feyerabend [3] adopts a very different approach with his theory on the 'Conquest of Abundance', in which he suggests that individuals 'conquer abundance' and manage it with others, through the creation of organisations. The concept of 'abundance' refers to the unlimited availability of possibilities, by which all the current needs of people can be met, through the creation of production strategies based on cooperation principles among the various players of the process [4], on the willingness of all the involved parties to implement virtuous cooperation in the organisation of local

Table 1: A vocabulary of scarcity - sustainability and abundance - resilience.

\begin{tabular}{lll}
\hline & Scarcity - sustainability & Abundance - resilience \\
\hline Connotation & Structured & Unstructured \\
& Fear & Vision \\
Control & Curious \\
Closed & Open \\
Organisational & Fact & Experience \\
& Quantity & Quality \\
Horizon & Output & Outcome \\
\hline
\end{tabular}


construction chains [5]. According to this theory the separation between producers and consumers does not exist anymore, but today we talk about Prosumer, citizens become responsible for the space they live in, and organise to 'make' the space in the first person. Civic compliance, active and cooperative citizenship, develops urban resilience abilities and opens up to a culture of designing and building whose strength is the reference to what in sociological and anthropological research was recently defined as 'collective intelligence' [6]. In this respect, Jane Jacobs [7] wrote that what our cities need more 'is a richer and more complex diversity and a higher number of interacting functions', adding that such diversity cannot be created save thanks to the incredible number of individuals and organisations, with diversified ideas and objectives, that plan and act outside the official structures.

\section{MULTIDISCIPLINARY NETWORKS - COMMUNITY WITHOUT PROPINQUITY}

In their theory of Spiral Dynamics, Beck and Cowan [8] present a spiral model to describe human development (referred to as Meme), starting from the stone age ruled by nature and by the primitive instinct of survival, to a more complex holistic vision of the world. If the approach to scarcity dominates the base of Beck and Cowan's spiral, this fades away at its higher layers, corresponding to the current stages of development. Currently the western world seems to be living mostly in the transition phase between the fifth and sixth level (from orange to green), where personal achievement which leads individuals to act rationally for their own advantage disagrees with the care for the community and personal growth, equality and the focus on the environmental problems. Here the mind-set of scarcity loses its influence. The issues tackled in the green layer of the spiral require different problem-solving strategies, hierarchies are less important, while personal contact, learning from others, belonging to a (virtual or real) community become appropriate strategies and the mind-set of abundance comes into play.

After all, the new experiences of online platforms of sharing economy, prove how the economic and social value is not just produced through the contents but also through participation and cooperation. This model provides the ability to change the use of goods and services instead of owning them, as stated Jeremy Rifking [9] defining the sharing economy the "third industrial revolution.'

The Internet and the digital environment are not just changing the rules of power distribution, promoting a more decentralised system based on the sum of all the minor potentials of networking, but also the sense of community. Traditionally the word community refers to a group of people with something in common and living in the same place. With the development of a technological society the second part of this definition has weakened and then faded away [10]. The concept of community without propinquity states that individuals, despite being far from each other, have different things in common and are organised in communities, exchanging information, processing and accomplishing projects. Levy again argues that 'the collective intelligence refers to this ability of the virtual community to stimulate the combined competence of its members'. As a consequence, with Peter Walsh [11], competence and knowledge become increasingly interdisciplinary through the aid of a diverse community.

Urban planning is about open source urban planning, representing the shift from a topdown planning vision, of traditional urban planning, to a bottom-up vision, proposing the central role of self-organisation as a consequence of the interaction and collaboration of large and diverse groups of people like those who live in the city. Accordingly, participation 
becomes the driver of the process, understood as debate and resolution, but in particular as direct action in the 'building' of the city [12].

From what has been said above, it emerges that all the local intervention processes, including urban regeneration strategies, today should be aimed at promoting actual processes of Collective Intelligence, which bring citizens back to the centre of transformation and management processes of the territory they live in; in this way the citizen is back to playing the leading role of local culture and identity. Citizens can participate in a multidisciplinary network to implement a collective creation process, changing the space they live in to adapt it to their needs. A shift from delegation to participation, from choosing to make recreates a new bond of people, resources and spaces.

\section{THE PARADIGMS OF PARTICIPATION}

Despite the predominance of models - typical of traditional urban planning - which have made community participation marginal, we can retrace some counter-current experiences developed by movements of citizens who have taken back the decision-making process, both at a community and urban level (see projects Nevicata 14, Yorokobu, Park(ing)Day, Leefstraat etc.). Such examples were useful to identify some useful paradigms to guide the methodological and operational choices for regeneration processes based on the creative abilities of the inhabitants.

\subsection{Co-responsibility of users - evolutivity of the functions}

The speed at which the market changes, the uncertainty of the tastes and the interests of consumers make spaces unable to be rigidly characterised based on a function, but need to be flexible to be readapted to the needs that users are faced with from time to time. The failure of functional zoning seems to fall, at the building scale, within the intended uses of the spaces,



Figure 1: Example of regeneration processes based on the creative abilities of inhabitants. 
which today are too subject to the fast-changing market and the uncertainty of the tastes and interests of consumers, to be submitted to rigid functional rules. After all the ambiguity of relationships that humankind weaves within a community is such that the space that materialises these relationships reflects their own ambiguity. This is why spaces cannot be rigidly characterised based on the function they currently host, but should be able to adapt to different uses and configurations over time.

This results in a new 'evolutive' concept of service, based on a time programming and management in progress of the human and physical intervention of the building. Where today a space is defined a priori for the positioning of an activity or a service, a new programmatic flexibility model is based on a 'logistically open' structure, programmable by subsequent additions and 'self-evolutionary' from an organisational point of view (in which the evolution of a part leads to the evolution of the whole). In reclamation activities of existing buildings it is necessary to enable a process in which the community strengthens its sense of community through a civic commitment to manage reclaimed spaces. An interesting example is the PARK(ing)Day project, an annual worldwide event where citizens, artists and activists work together to temporarily transform pay and display parking spaces into temporary public spaces. A typically 'open source' project, started from the transformation of a parking lot into a temporary public park in a San Francisco area, it was then adopted to tackle a number of social issues in various urban contexts, making free health clinics, art installations, bike repair shops etc. PARK (ing) Day is held every year on the third Friday of September, in hundreds of cities all over the world.

\subsection{Localism - prosumer}

Historically, development is only considered possible if associated with economic growth. Today the word 'development' is often followed not just by the word 'economic', but by other adjectives such as 'auto-centric', 'endogenous', 'integrated', 'authentic', 'autonomous and of the people', 'fair', adding a social dimension to economic growth, establishing the central role of humankind in the economy. Today we talk about social, local, human and durable development or about 'micro-development'. Outside traditional circuits, relational relationships are promoted, based on multi-disciplinary networks, on the creation of economic and 'social drawers' compared to family strategies, but transferred to a broader social group [13].

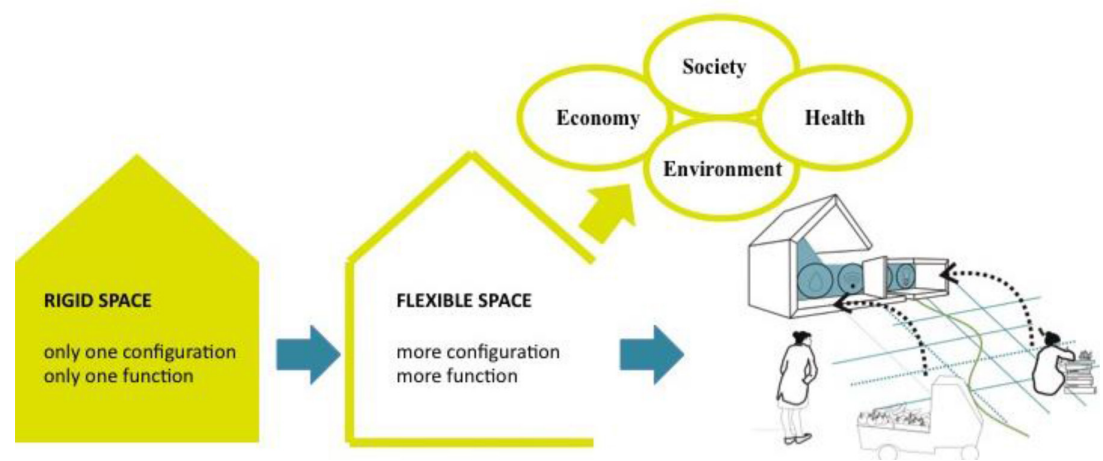

Figure 2: From rigid space to flexible space. 
In these new clans, citizens start being prosumers, a concept associated with that of collective intelligence, because the result of a work of people who are prosumers is produced and consumed according to such obligation of giving, receiving and reciprocating as analysed by Marcel Mauss [14]. The numerous attempts, everywhere, of short production chains of organic products, local buying groups, farmers' markets in the city are an example of this, aiming at creating a self-sustainable management model of common property and the territory and its farming resources with the direct participation of the local community, to increase the level of resilience, autonomy of external socio-economic unbalances and turn the village or the neighbourhood into an integrated space of recreational, teaching and production activities, in which people of different ages and conditions can meet and work together, producing and consuming social capital.

\subsection{Co-creation - Networking - Crowdfunding}

The relationship between these paradigms means forgetting the public development and thinking in terms of 'cultural citizenship' and of collective sense process. The public space is not a stage, but a co-creative space, whose success does not depend on the initiative of a few, but on the collective thinking and action of many, who implement a collective creation process with a few resources and contribute to the creation of a smart user-centred territory. At the base of this cultural development process, there's the networking of citizens and professionals with different skills, able to obtain funding and other resources to support their initiatives. An example is the Spanish cooperative Basurama, established in 2001 at the Higher Technical School of Architecture of Madrid, today it exports its provocative projects in Europe and Latin America. It is an alternative architecture firm or a social design enterprise, as its founders define it, aimed at recovering deteriorated urban spaces, by recycling non-reusable objects and materials and with the participation of local communities. Another interesting project is WiMBY (Welcome into my back yard!) by Crimison Architectural Historias, that since 1999 works on the requalification of Hoogvlielt, a 60's New Town near Rotterdam. The main objective of the project is requalifying Hoogvlielt through a multidisciplinary group of architects, residents, entrepreneurs, institutions, researchers, through the development and implementation of a series of architecture, urban-planning and sociology projects and programmes.
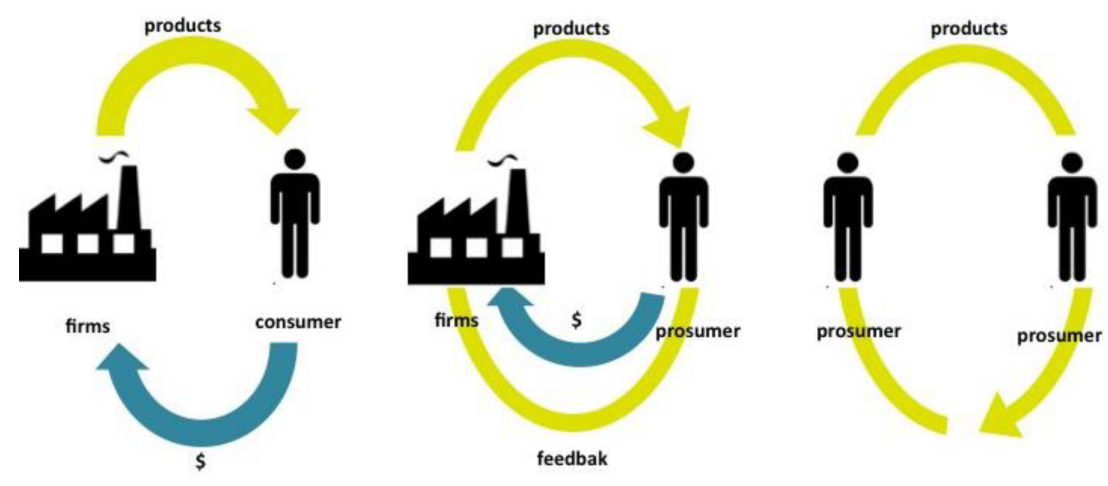

Figure 3: Evolution from consumer/producer to prosumer. 


\section{CONCLUSIONS}

The implementation of participatory processes based on these paradigms implies:

- at a user's level, that every citizen/user involved in such processes, despite lacking disciplinary or technical knowledge, can propose criticisms or useful suggestions to improve the quality of interventions or be directly involved in the making phase. The implementation of such processes also helps the citizens build their identity, acquire new faith in their ability to act and change reality, generating new social, intellectual and political abilities.

- at an operational level, the adaptability of times, ways and tools to the personal and professional characteristics of the parties involved and the context in which the process is performed, as a consequence, even if driven by one method, each project has a profile and gives outcomes.

- at an urban level, the development of a city model characterised by a programmatic complexity. This territorial organisation is based on the principle of 'easy change' over time, in relation to the variable needs of the users, and a simple interface, through technical and procedural solutions able to trigger a profitable exchange between those who live in the city and those who design it.

- at a territorial level, a multiplying effect propagating the application of these strategies to other contexts, too.

\section{REFERENCES}

[1] UNEP, Climate Change. The Role of Cities, Nairobi, 2005.

[2] Achterhuis, H.J., The empire of scarcity, from thomas hobbes to michel foucault. In Dutch: Het Rijk der Schaarste: van Thomas Hobbes tot Michel Foucault, Ambo Baarn, 1988.

[3] Feyerabend, P., Conquest of Abundance, a Tale of Abstraction Versus the Richness of Being, ed. B. Terpstra, The University of Chicago Press: Chicago and London, 1999.

[4] Del Nord, R., Does the market demand a different kind of research? Techne - Journal of Technology for Architecture and Environment, n.1, Florence University Press, pp. 7075, 2011.

[5] Campioli, A., Architectural quality: innovation, technological research and design. Techne - Journal of Technology for Architecture and Environment, n. 1, Florence University Press, 61-68, 2011.

[6] Lévy, P., L'intelligence collective. Pour une anthropologie du cyberspace, Editions La Découverte, Paris, 1994.

[7] Jacobs, J., The Death and Life of Great American Cities, Random House: New York, 1961.

[8] Beck, E. \& Cowan, C., Spiral Dynamics: Mastering Values, Leadership and Change, Blackwell Publishing, 1996.

[9] Rifking, J., La terza rivoluzione industriale, Mondadori: Milano 2011.

[10] Raymond, L., La città sostenibile, partecipazione, luogo, comunità, Elèuthera: Milano, 1998.

[11] Walsh, P., That withered paradigm: the web, the expert, and the information hegemony. In Democracy and New Media, eds. H. Jenkins \& D. Thorburn, MIT Press, 2004.

[12] Freire, J., Urbanismo emergente. En Deseo de ciudad: Arquitecturas revolucionarias, ed. Cristina García-Rosales, Mandala EdicionesPeter Walsh, 2010.

[13] Latouch, S., Breve trattato sulla decrescita felice e Come sopravvivere allo sviluppo, Bollati Boringhieri: Torino, 2015.

[14] Mauss, M., Saggio sul dono. Forma e motivo dello scambio nelle società arcaiche, Einaudi: Torino 2002. 